\title{
Computational Fluid Dynamics Modelling of the Microclimate within the Boundary Layer of Leaves Leading to Improved Pest Control Management and Low-Input Greenhouse
}

\author{
Hicham Fatnassi ${ }^{1, *}$, Thierry Boulard ${ }^{2}$, Christine Poncet ${ }^{2}$, Nikolaos Katsoulas ${ }^{3}{ }^{(0)}$, Thomas Bartzanas ${ }^{4}$, \\ Murat Kacira ${ }^{5}$, Habtamu Giday ${ }^{1}$ and In-Bok Lee ${ }^{6}$ \\ 1 International Center for Biosaline Agriculture, Dubai 14660, United Arab Emirates; \\ h.gebraegziabher@biosaline.org.ae \\ 2 Université Côte d'Azur, INRAE, CNRS, UMR ISA, 06000 Nice, France; th.boulard@free.fr (T.B.); \\ christine.poncet@inrae.fr (C.P.) \\ 3 Department of Agriculture Crop Production and Rural Environment, University of Thessaly, \\ 38446 Volos, Greece; nkatsoul@uth.gr \\ 4 Department of Natural Resources Management and Agricultural Engineering, \\ Agricultural University of Athens, 11855 Athens, Greece; thomas.bartzanas@gmail.com \\ 5 Department of Biosystems Engineering, College of Agriculture and Life Sciences, University of Arizona, \\ Tucson, AZ 85721, USA; mkacira@arizona.edu \\ 6 Laboratory of Aero-Environmental Engineering, Department of Rural System Engineering College of \\ Agriculture and Life Science, Seoul National University, Seoul 08826, Korea; iblee@snu.ac.kr \\ check for \\ updates \\ Citation: Fatnassi, H.; Boulard, T.; \\ * Correspondence: h.fatnassi@biosaline.org.ae
} Poncet, C.; Katsoulas, N.; Bartzanas, T.; Kacira, M.; Giday, H.; Lee, I.-B. Computational Fluid Dynamics Modelling of the Microclimate within the Boundary Layer of Leaves Leading to Improved Pest Control Management and Low-Input Greenhouse. Sustainability 2021, 13, 8310. https://doi.org/10.3390/ su13158310

Academic Editors: Georgios Ntinas and Dennis Dannehl

Received: 10 June 2021

Accepted: 1 July 2021

Published: 26 July 2021

Publisher's Note: MDPI stays neutral with regard to jurisdictional claims in published maps and institutional affiliations.

Copyright: () 2021 by the authors. Licensee MDPI, Basel, Switzerland. This article is an open access article distributed under the terms and conditions of the Creative Commons Attribution (CC BY) license (https:// creativecommons.org/licenses/by/ $4.0 /)$.

\begin{abstract}
This work aims at using the Computational Fluid Dynamic (CFD) approach to study the distributed microclimate in the leaf boundary layer of greenhouse crops. Understanding the interactions in this microclimate of this natural habitat of plant pests (i.e., boundary layer of leaves), is a prerequisite for their control through targeted climate management for sustainable greenhouse production. The temperature and humidity simulations, inside the greenhouse, were performed using CFD code which has been adapted to simulate the plant activity within each mesh in the crop canopy. The air temperature and air humidity profiles within the boundary layer of leaves were deduced from the local surrounding climate parameters, based on an analytical approach, encapsulated in a Used Defined Function (UDF), and dynamically linked to the CFD solver, a work that forms an innovative and original task. Thus, this model represents a new approach to investigate the microclimate in the boundary layer of leaves under greenhouses, which resolves the issue of the inaccessibility of this area by the conventionnel measurement tools. The findings clearly showed that (i) contrarily to what might be expected, the microclimate parameters within the boundary layer of leaves are different from the surrounding climate in the greenhouse. This is particularly visible during photoperiods when the plant's transpiration activity is at its maximum and that (ii) the climatic parameters in the leaf boundary layer are more coupled with leaf surfaces than with those of greenhouse air. These results can help developing localized intervention strategies on the microclimate within boundary layer of plant leaves, leading to improved and sustainable pest control management. The developed climatic strategies will make it possible to optimize resources use efficiency.
\end{abstract}

Keywords: CFD modeling tool; leaf boundary layer microclimate; smart microclimate control; sustainable pest management

\section{Introduction}

Knowing which factors contribute to the elaboration of the microclimate in the natural habitats of plants pests, is crucial for the development of non-chemical methods of plant protection [1]. According to Jones et al. [2], insects and mites usually spend most of their 
time within the boundary layer of leaves which, thanks to its physiological activity, has a different microclimate compared to surrounding climate conditions. Several factors are involved in the development of the microclimate in this area related either to plant activity or to surrounding climatic parameters such as plant transpiration, air temperature, relative humidity, airflow, and solar radiation [3]. Thus, the climatic parameter variations inside the greenhouse strongly impact the microclimate within the leaf boundary layer which, in turn, influences all pest activities during their life cycle (oviposition, reproduction, predation, etc.).

However, as stressed by Woods and Potter [4]: we know disproportionately a lot about environments around big things but astonishingly little about environments around small things. To fill this gap and to explore this unfamiliar environment, several experimental studies have already been carried out to lift the veil on the microclimate in the boundary layer of leaves. Sheriff [5] is among the first researchers to inspect the microclimate in this inaccessible area and was able to measure the humidity gradient close to the leaf of Nicotiana glauca. In their study, Grace and Wilson [6] measured the air flow closely around a Populus leaf using a hot-wire anemometer, and Boulard et al. [1,7] characterized the gradient of temperature and humidity in the tomato leaf boundary layer at three locations in the greenhouse using a dual approach combing measurement and modelling. Indeed, using an analytical approach, Boulard et al. [1] were able to model the temperature and humidity profiles across the boundary layer of the lower side of greenhouse tomato leaves and validated these simulations using the localized air's relative humidity and temperature measurements. They later analyzed the relationship between the leaf boundary layer climate and air velocity within the whole greenhouse space [7] and highlighted the strong heterogeneity of the climate parameters at leaf surface, particularly air humidity, mainly under the dependence of the spatial distribution of the convective regime.

Katsoulas et al. [8] used artificial rose leaves to evaluate the leaf boundary layer's conductance in a greenhouse under different ventilation regimes, while more recently, Kimura et al. [9] used artificial tomato leaves to evaluate the leaf boundary layer's conductance under different regimes of environmental control, and while Nikolaou et al. [10] presented an approach to estimate the leaf boundary layer's conductance in a Mediterranean greenhouse based on instantaneous leaf temperature measurements.

Nevertheless, given the complexity of measuring climatic parameters in the boundary layer of leaves, most of researchers have chosen the modeling approach to explore the environment in this natural habitat of pests. Ferro and Southwick [11] presented a model which estimates the relative humidity within the leaf boundary layer that constitutes the microhabitat for leaf-inhabiting arthropods. Roy et al. [12] simulated air temperature and humidity using a CFD model at bean leaf surface for low light levels. The plant model was associated with the CFD model which produced predictions of the environmental variables in good agreement with experimental measurements on Munger cells with a single bean leaf.

Despite this extensive research, most studies investigated only considering local boundary layer climate of a single leaf and not considering the boundary layer microclimate of the plant canopy in the greenhouse.

To extend this microclimatic characterization to the whole plant canopy in the greenhouse, the present study aims at using a CFD model to explore the distribution of climatic parameters within the leaf boundary layer of all plants in the greenhouse.

This model forms an original and innovative work in the field since it allows to give useful information on the microclimate in this inaccessible area and to establish the link between the climate in this leaf boundary layer and the surrounding climate in the greenhouse.

Based on the recent advances in the study of pest infestation dependence on local climate parameters [13], this model can later serve as a predictive and decision support tool to prevent pest infestation and offer sustainable pest management practices in the greenhouses. 


\section{Materials and Methods}

\subsection{The Greenhouse}

The model developed in this study was applied to a four-span arched type plastic greenhouse (Figure 1): $4 \times 9.6 \mathrm{~m}$ wide, $80 \mathrm{~m}$ long and $5.90 \mathrm{~m}$ ridge height (4 $\mathrm{m}$ eave height) The greenhouse is ventilated by convection through $1.5 \mathrm{~m}$ wide continuous ridge openings (Figure 1).

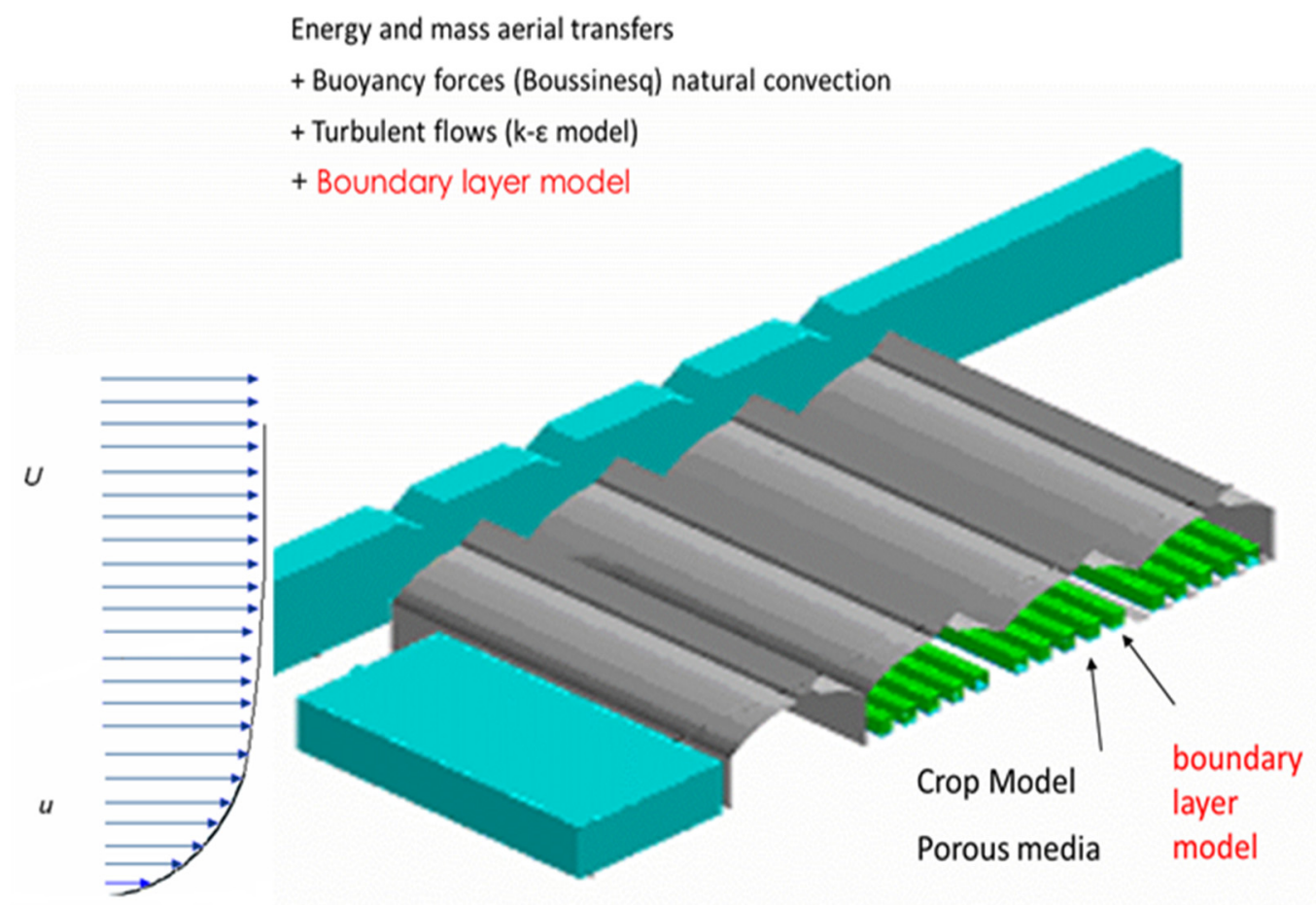

Figure 1. Summary of the different models used to simulate the microclimate in the greenhouse and in the boundary layer of plant leaves.

A virtual rose crop arranged in a form of $2 \mathrm{~m}$ high was used to simulate the crop activity inside the greenhouse.

\subsection{The Numerical Model}

The developed model is composed of different scales of modeling that describe the diverse components that make up the greenhouse and crop environment and their relevant heat and mass exchanges.

The main model reproduces airflow, heat and mass transfer inside the greenhouse and its surrounding area is governed by the Navier-Stokes and energy equations. In addition, a crop model has been associated with the main CFD model to simulate airflow and mass exchanges within the crop cover assimilated to a porous medium considering two major phenomena:

The dynamic effect of the crop cover on air flow $S_{c}$ is expressed by unit volume of the cover by the commonly used formula [14]:

$$
S_{c}=-L A D C_{d} \rho u^{2}
$$

where $u$ is the air speed within the crop cover, $L A D$ is the leaf area density, and $C_{d}$ is a drag coefficient.

To include the drag effect proportional to the leaf density into our CFD study, the crop cover was considered as a porous medium, and the Darcy-Forsheimer equation was used:

$$
S_{c}=-\left(\left(\frac{\mu}{K}\right) u+\left(\frac{C_{F}}{K^{0.5}}\right) u^{2}\right)
$$


where $\mu$ is the dynamic viscosity of the fluid, $K$ the permeability of the porous medium, and $C_{F}$ is the non-linear momentum loss coefficient. For the low air speed values observed into the crop cover, the first term of Equation (2) can be neglected in front of the quadratic term. Then, combining Equations (1) and (2) yields:

$$
\frac{C_{F}}{K^{0.5}}=L A D C_{D}
$$

which is the latent and sensible heat exchanges with ambient air.

The exchanges of heat and water vapour between leaves and air are described by means of the heat and mass balances of leaves with the air (Figure 2). Each mesh of the crop cover is assimilated to a "volume heat source boundary condition" receiving a radiative flux $\left(G_{a b s}\right)$. This flux is partitioned into convective sensible $\left(S_{S}\right)$ and latent $\left(S_{L}\right)$ heat fluxes (water vapour) according to the following relations:

$$
\begin{gathered}
G_{a b s}=S_{S}+S_{L} \\
S_{S}=L A D \rho C_{P}\left(T_{l}-T_{a}\right) / r_{a} \\
S_{L}=\gamma L A D \rho C_{P}\left(q_{l}^{*}-q_{a}\right) /\left(r_{a}+r_{s}\right)
\end{gathered}
$$

where $r_{s}$ and $r_{a}$ are the stomatal and aerodynamic resistances between the virtual solid matrix representing the crop and characterized by its surface temperature $\left(T_{l}\right)$ and the air $\left(T_{a}\right) ; q_{l}^{*}$ and $q_{a}$ are the saturation-specific humidity at the leaf temperature and the specific humidity of air, respectively.

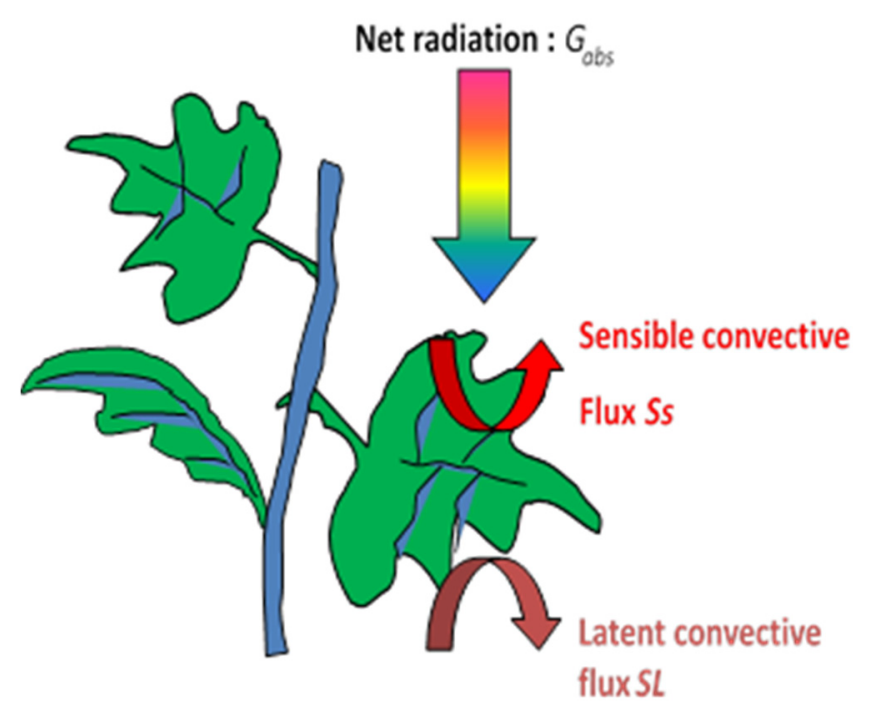

Figure 2. Schematic drawing of the exchanges of heat and water vapour between leaf and air.

Both couplings have already been amply studied and published in various studies performed in greenhouse conditions for lettuce crops [15], rose crops [14], single beans leaf [12], tomato crops [16-21], and impatiens crops [22], while the objective is to explore the microclimate inside the leaf boundary layer using an analytical model derived of the boundary layer theory [23].

\subsection{Numerical Modelling of the Microclimate in the Leaf Boundary Layer}

Air temperature and humidity profiles within the leaf boundary layer can be deduced from surrounding air velocity depending on Prandtl and Schmidt numbers [24]. Since the air velocity inside the greenhouse is lower than $1 \mathrm{~m} \mathrm{~s}^{-1}$ due to containment conditions, i.e., Reynolds number is smaller than 106 corresponding to the transition to turbulence, the convective transfer can be considered as laminar $[1,7,14,16,25]$. Consequently, temperature 
and specific humidity profiles across the leaf boundary layer can then be deduced from the following expressions [24]:

$$
\begin{aligned}
& T(\eta)=T_{a}+\left[0.0046 \eta^{3}+0.0108 \eta^{2}-0.3621 \eta+1.0005\right] /\left(T_{l}-T_{a}\right) \\
& q(\eta)=q_{a}+\left[0.0093 \eta^{3}+0.0248 \eta^{2}-0.2787 \eta+0.9969\right] /\left(q_{l}^{*}-q_{a}\right)
\end{aligned}
$$

where $\eta$ is the non-dimensional variable distance:

$$
\eta=y \sqrt{\frac{u_{a}}{v x}}
$$

$y$ being the distance from the wall; $x$ the distance from the windward end of the leaf surface; $u_{a}$ is the non-disturbed air speed and $v$ is the dynamic viscosity of air; the subscripts $l$ and $a$ refer to the leaf and the bulk air, respectively.

The characteristic thickness of the boundary layer is given by the Blasius relation:

$$
\delta_{l} \approx 4.92 \sqrt{\frac{v l}{u_{a}}}
$$

On an experimental point of view, this boundary layer model was amply validated by Boulard et al. [1,7] with respect to tomato leaves using micro thermo-hygrometers whose protection caps were removed to precisely sense temperature and humidity conditions at distances of 5 and $15 \mathrm{~mm}$ from the leaf surface together with omni-directional hotball anemometers to sense air speed in leaf vicinity. Model validation was successfully performed as illustrated by the details of the measurements presented in the two previously cited papers.

These temperature and air relative humidity distribution of microclimate at leaf surface, based on the boundary layer theory, were input in the Used Defined Functions (UDF) describing the sensible and latent heat exchanges between the air and the crop within each mesh of the crop canopy. This UDF was dynamically linked with the solver Fluent of Ansys software to the parallel solving of the climate parameter equations inside the greenhouse and inside the crop leaves boundary layer (Figure 3).

\subsection{The Boundary Conditions}

The boundary conditions deduced from the measurements were imposed at the greenhouse wall level. An inlet logarithmic velocity profile corresponding to the measured wind was imposed outside the greenhouse together with the measured solar radiation, temperature, and humidity values.

Using the developed model, we studied the microclimate in the leaf boundary layer of all plants in the greenhouse. A sensitivity study was also carried out to study the effects of varying the environmental factors in the greenhouse on the microclimate in the leaf boundary layer. 


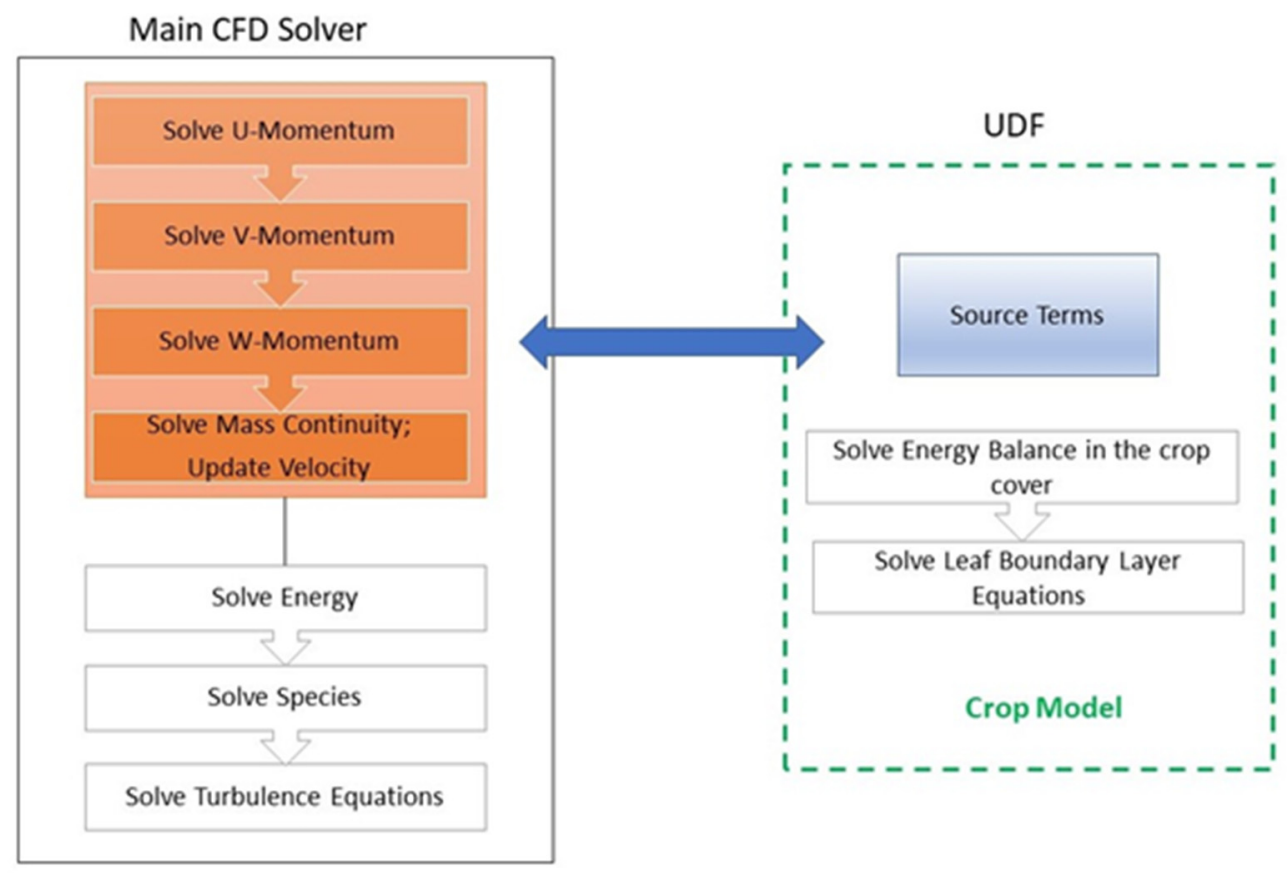

Figure 3. Diagram of User Defined Function UDF for crop and boundary layer models linked to the main solver in the CFD model.

\section{Results and Discussion}

The results of the effects of the different case studies performed on the distributed climate and the boundary layer of the plant leaves of the studied greenhouse and their analyses in relation to the surrounding climate parameters are presented in the following sections.

\subsection{Leaf Boundary Layer Climate Analysis}

\subsubsection{Leaf Boundary Layer Thickness}

As shown in Figure 4, which presents the temporal evolution of the boundary layer thickness and air velocity in the crop cover, these two variables are inversely proportional. The leaf boundary layer is thick in the area where the velocity of the surrounding air is low and vice versa.

According to this figure, a difference in the thickness of this boundary layer was observed between day and night. This difference can be explained by the containment level of the greenhouse. In fact, the greenhouse is closed at night, which reduces the air velocity in the greenhouse, and conversely, the vent openings during the day increases air circulation.

\subsubsection{Temperature and Humidity in the Leaf Boundary Layer}

Figures 5 and 6 display the temperature and humidity patterns in the boundary layer at various distances from leaves ( $1 \mathrm{~mm}, 5 \mathrm{~mm}, 10 \mathrm{~mm}$, and $15 \mathrm{~mm}$ from under leaf surface) together with temperature and humidity of ambient air outside the boundary layer and at leaf surface.

Considering the temperatures trends, we notice that during the daytime the ambient air temperature and leaf temperature are, on average, generally close. Consequently, the temperature field in the leaf boundary layer is also limited inside this narrow range. However, during nighttime, one can observe a systematically higher temperature gap between the ambient air and the leaf (the leaf being slightly warmer) ranging between $1{ }^{\circ} \mathrm{C}$ (1-6 August) and $2{ }^{\circ} \mathrm{C}(7-13$ August). 


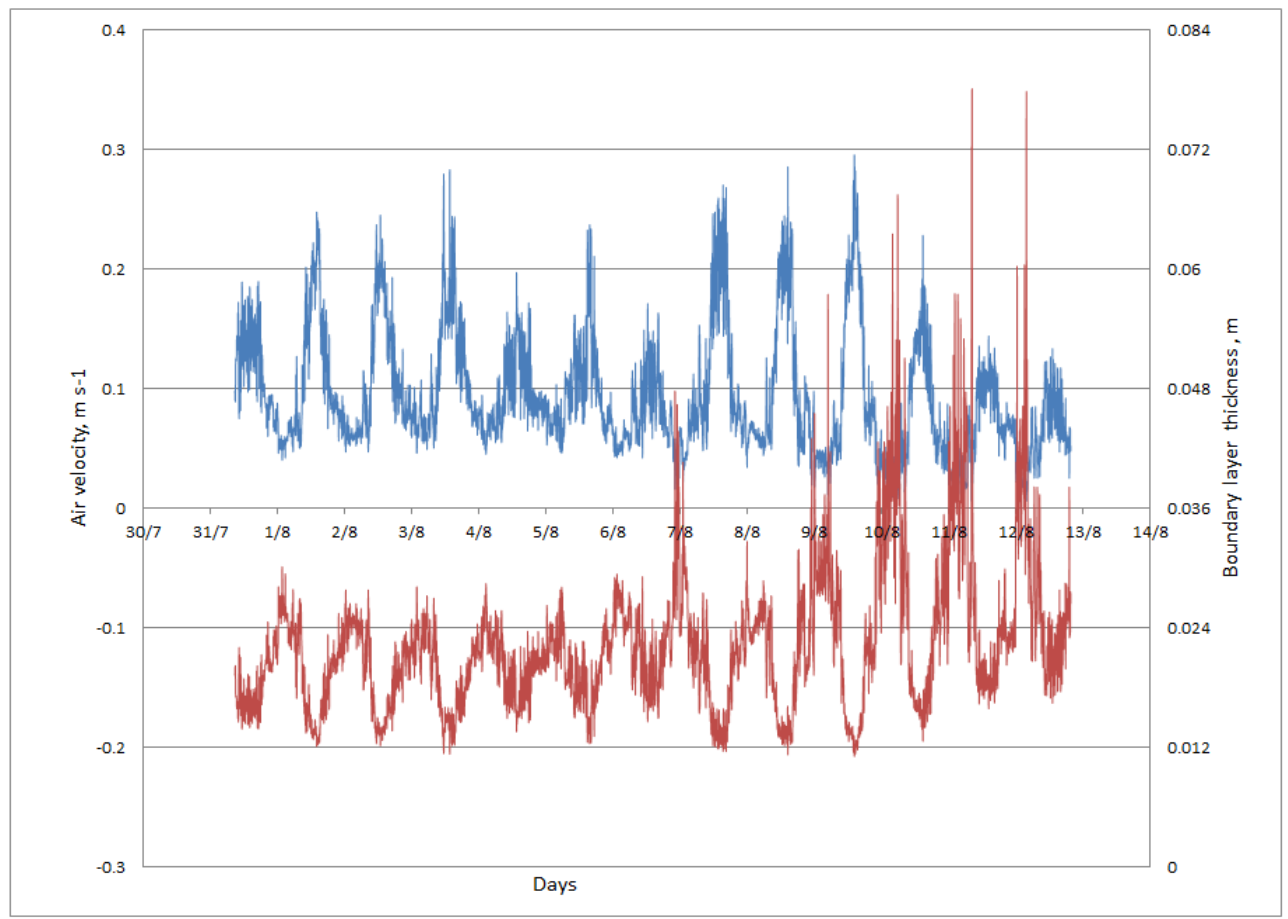

Figure 4. Time evolution of leaf boundary layer thickness (brown color) as a function of surrounding air velocity (blue color).

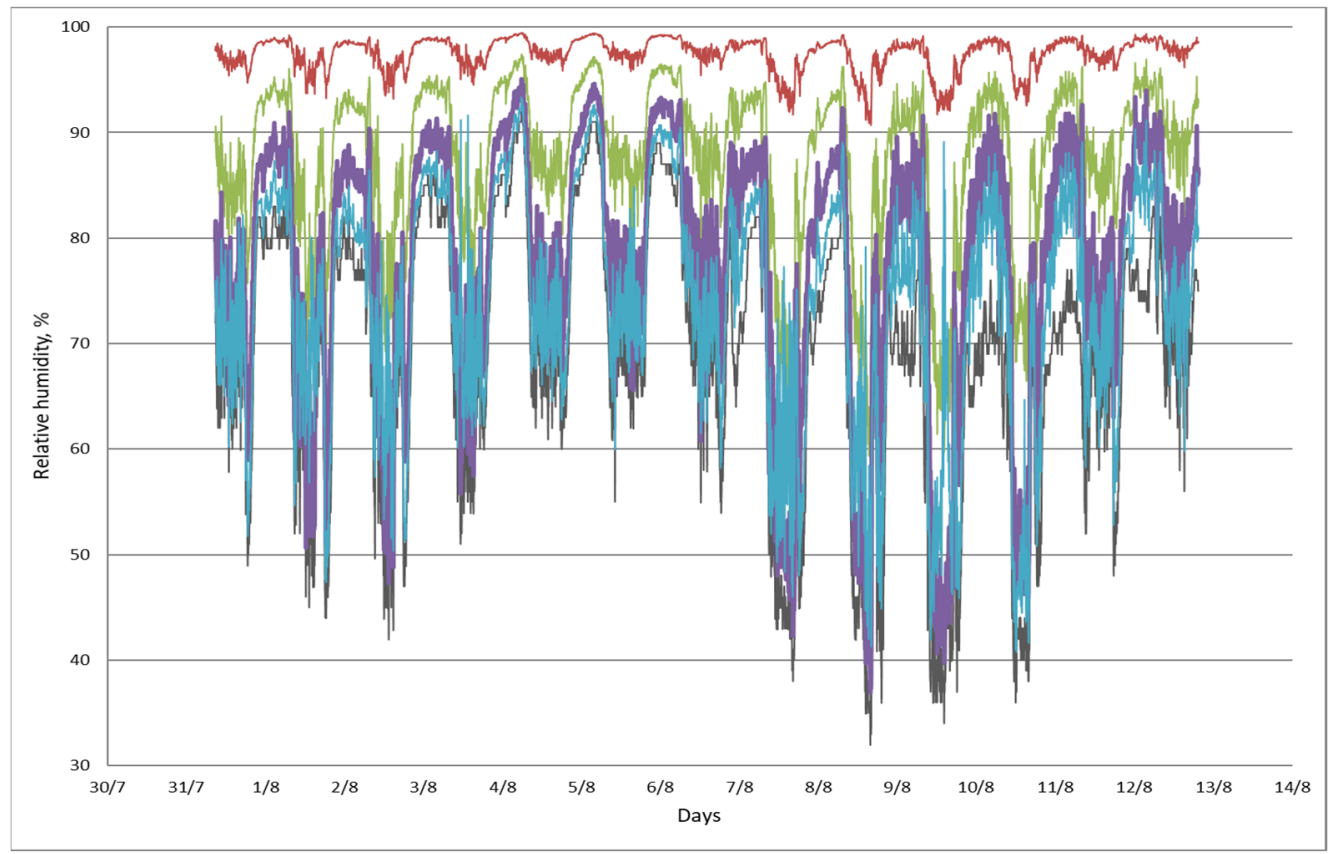

Figure 5. Simulated air humidity within the boundary layer of leaves over time: relative humidity of ambient air (black color); relative humidity at $1 \mathrm{~mm}$ from the leaf (brown color); relative humidity at $5 \mathrm{~mm}$ from the leaf (green color); relative humidity at $10 \mathrm{~mm}$ from the leaf (purple color); relative humidity at $15 \mathrm{~mm}$ from the leaf (sky blue color).

In the boundary layer of leaves, no large difference in temperature were observed between the different layers along this area during the daytime. During the nighttime, the temperature at $1 \mathrm{~mm}$ is close to the temperature of leaf surface while the temperature at $15 \mathrm{~mm}$ is close to the ambient air. The temperatures values at 5 and $10 \mathrm{~mm}$ are in between. 


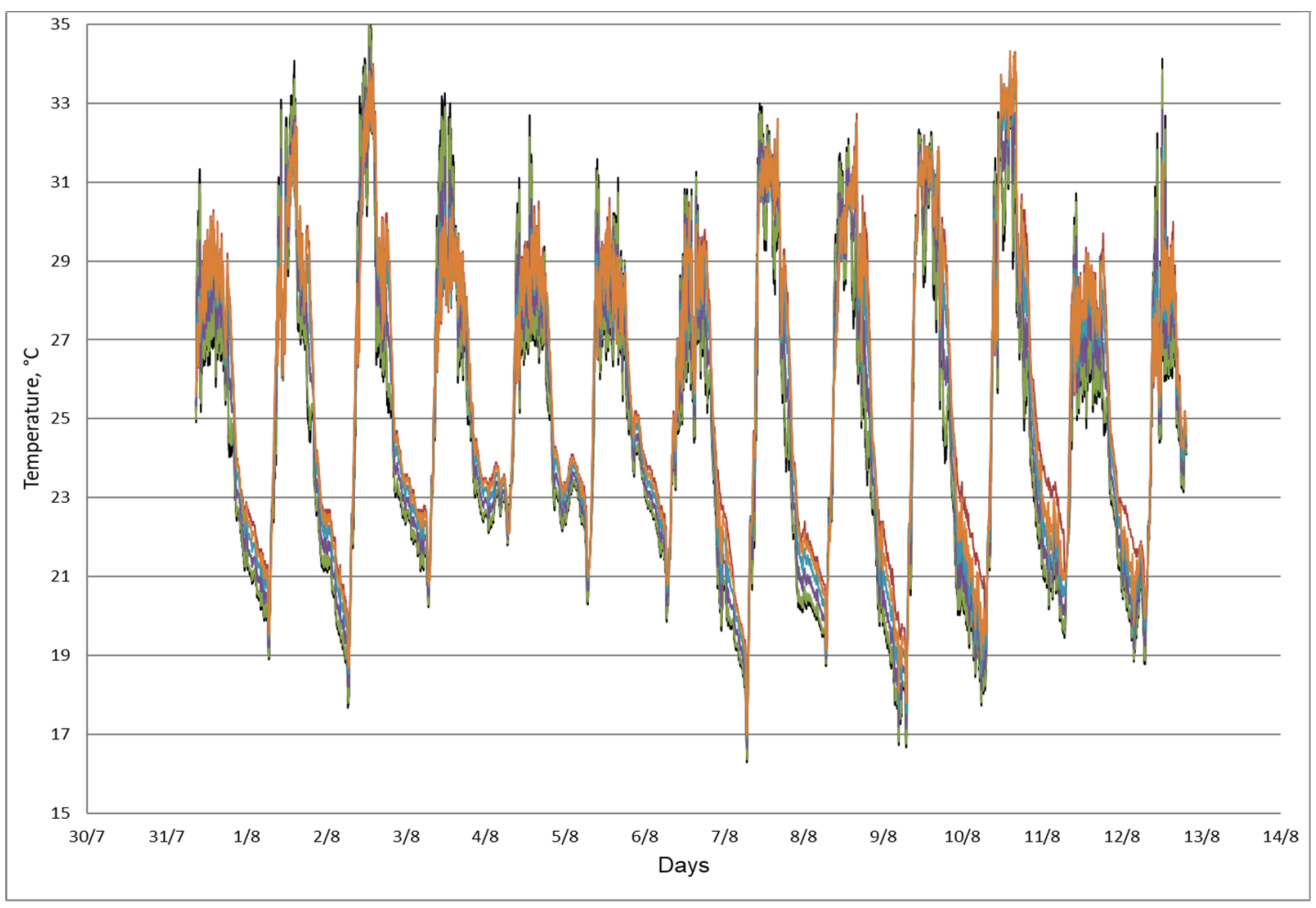

Figure 6. Simulated air temperature within the leaf boundary layer of crop rose over time: temperature of leaf (black color); temperature of ambient air (brown color); temperature at $1 \mathrm{~mm}$ from the leaf (green color); temperature at $5 \mathrm{~mm}$ from the leaf (purple color); temperature at $10 \mathrm{~mm}$ from the leaf (sky blue color); temperature at $15 \mathrm{~mm}$ from the leaf (orange color).

This can be explained by the difference of the thickness of the boundary layer between daytime and nighttime. A thick boundary layer reduces the heat transfer between the leaf and the surrounding environment.

A zoom in on three days (Figure 7) on the graph of air temperature at $1 \mathrm{~mm}$ from the lower surface of leaves and the ambient air further clarifies this discontinuity between the leaf boundary layer and the surrounding climate.

This layer of one millimeter under the leaf is the area where the body of the insects is included. Indeed, the body circumference of most plant pests is less than one millimeter.

This zone protects pest eggs from extreme ambient temperatures [26] and provides a favorable environment for their development.

The air humidity course is quite different from the temperature one as a strong discontinuity between the boundary layer and the ambient air can be observed. Due to leaf transpiration, particularly through the lower side of the leaves, air humidity is saturated at the leaf surface and is much higher in the leaf boundary layer. However, this gap is less marked at night than during daytime because the rose's stomata, as a great variety of plants, are open only during daytime and closed at night. This is not a common rule as an adaptation to arid climatic conditions certain species undergoing CAM photosynthesis, e.g., the pineapple have their stomata opened at night and closed during daytime to reduce transpiration. Thus, the leaf boundary layer's climate is directly related to the physiological response of crops and especially transpiration. The stomata have a maximum aperture when sunlight is high at noon and from then on closure takes place, slowly at first and faster by the end of the day. When stomata are open, an evapotranspiration rate occurs due to the water potential gradient and air humidity increasing up to saturation close to the lower leaf surface and, thanks to the decrease in momentum transfer, contributes to the creation of a climate discontinuity between the boundary layer and the ambient air surrounding the leaf. 


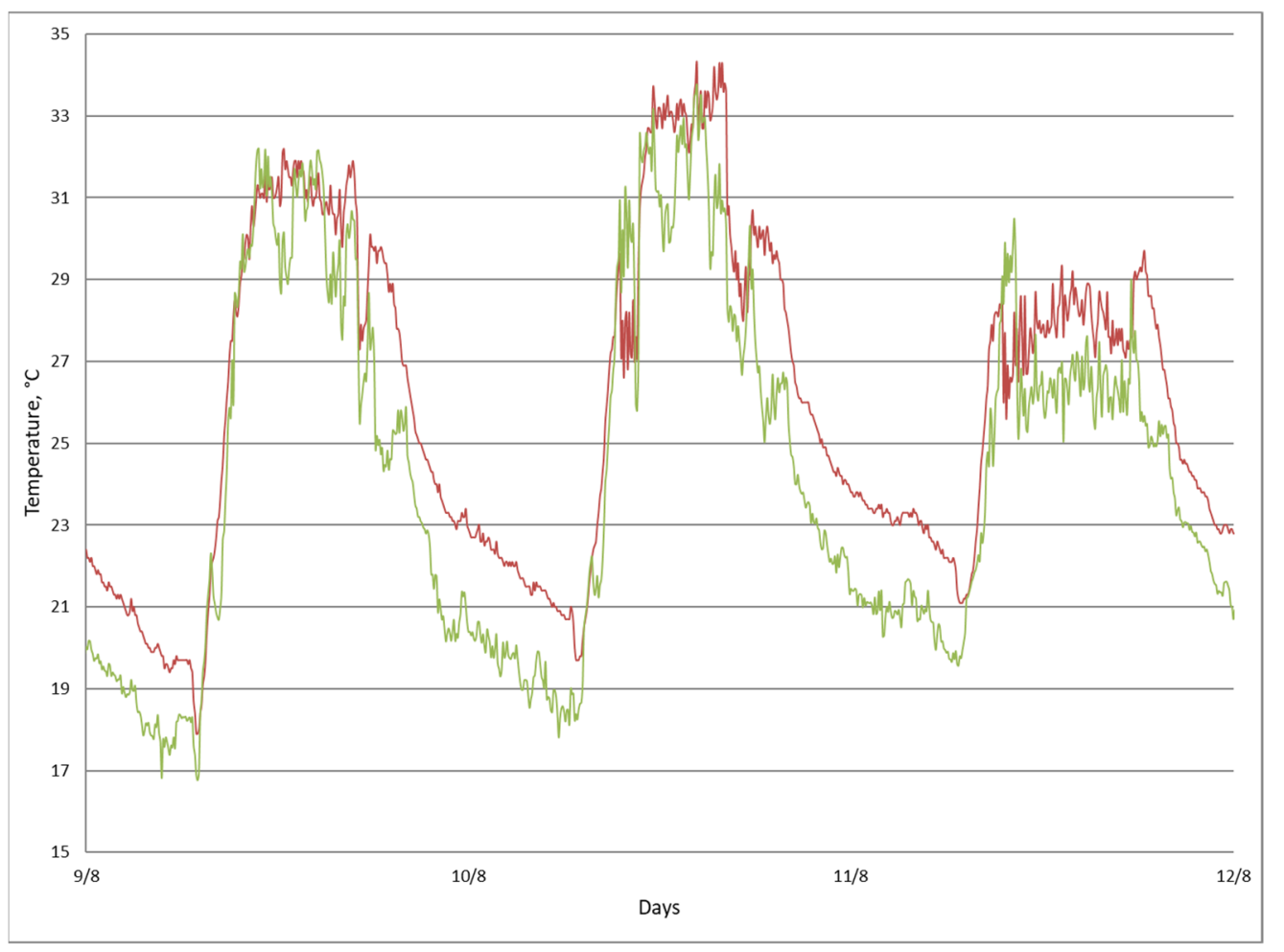

Figure 7. Zoom in on three days of simulated air temperature at $1 \mathrm{~mm}$ from the lower part of the leaf (green color) and the ambient air (brown color) over time.

These results are in a very good agreement with the experimental results of Boulard et al. [7] in tomato and of Sheriff [5] in Nicotiana glauca who highlight the humidity gradients close to the lower surface of the leaf. The main novelty of our study is to show that the boundary layer microclimate distribution throughout the greenhouse is also directly related to the inside climate heterogeneity, as illustrated by Figures 8 and 9 , showing temperature and humidity distributions at the level of the leaf boundary layer and ambient climate inside crop rows, respectively.

The air temperature field during daytime within the leaf boundary layer in the crop row (Figure 8) is marked, as in ambient air, by a four-degree temperature gradient between the top and base of the canopy due to a higher incident radiation at the top. Therefore, boundary layer climate reveals no important discontinuity as ambient air and leaf temperature are quite similar and confirms the information given in Figure 6 and analyzed before.

During daytime, the air humidity field within the leaf boundary layer in the crop row (Figure 9) highlights gradients between the base and the top of the crop cover. Under low air velocities prevailing at the base of the crop rows, the boundary layer is thicker, and as transpiration is still important, the air humidity is higher.

The observed discontinuities between the humidity at the boundary layer and in the ambient air prove that to improve the crop disease control, the microclimate conditions at this level must be directly targeted rather than controlling the entire ambient air climate. More specifically, air humidity, the crucial parameter controlling pest activity, must not be considered in the air at the center of the greenhouse but in the crop cover at leaf level and techniques such as localized heating or ventilation to control the microclimate at this level should be implemented. 
$1 \mathrm{~mm}$ from

$5 \mathrm{~mm}$

$10 \mathrm{~mm}$

$15 \mathrm{~mm}$

Leaf surface
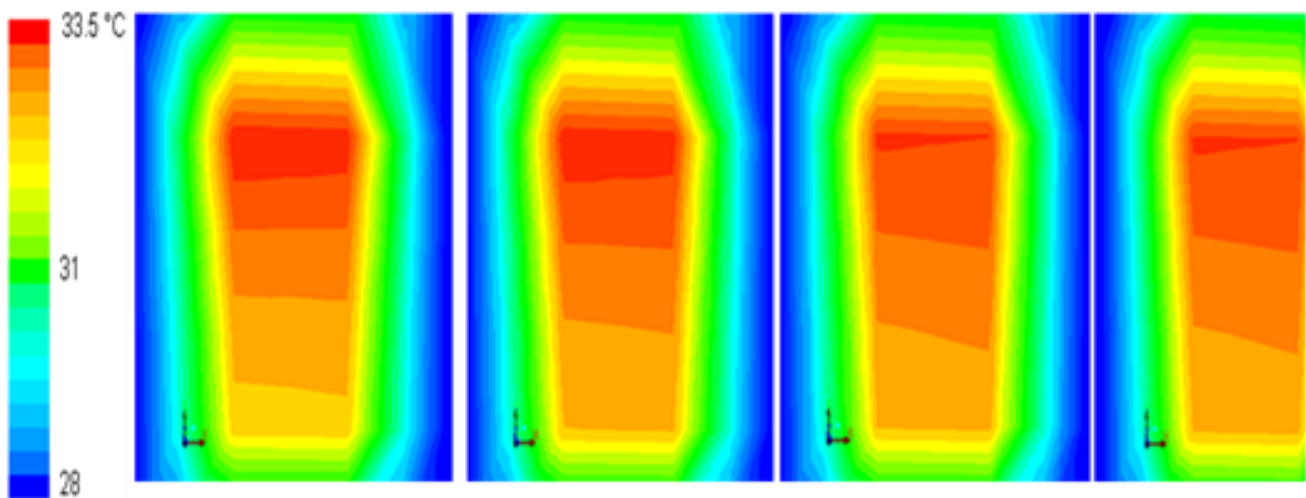

Figure 8. CFD simulation of the air temperature during daytime at different locations within the boundary layer of leaves of plants that form the crop row (A cross section along the vertical plane perpendicular to the axis of the crop rows).

$1 \mathrm{~mm}$

from the leaf surface
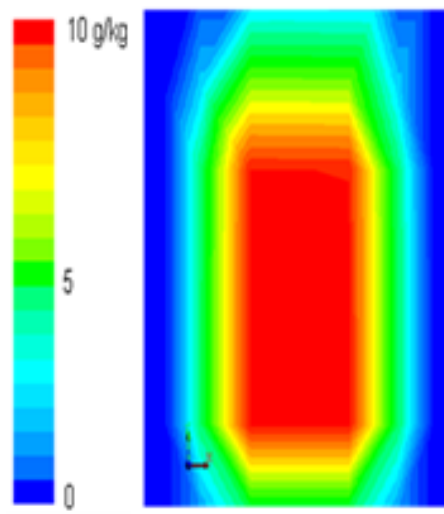

$5 \mathrm{~mm}$
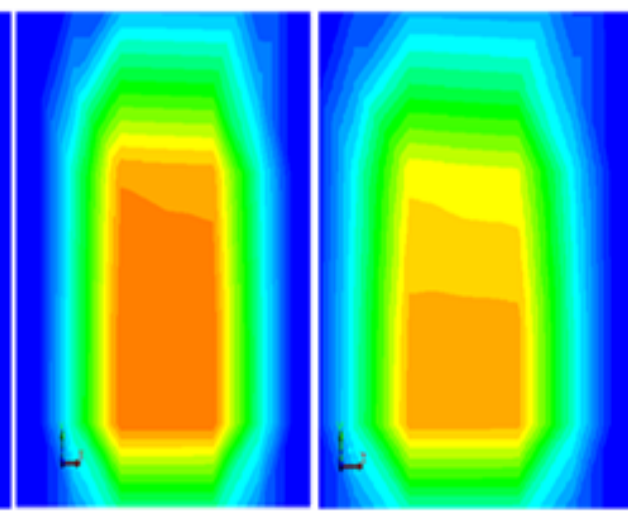

$15 \mathrm{~mm}$

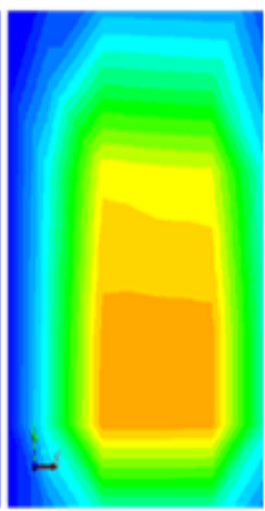

Figure 9. CFD simulation of the air humidity during daytime at different locations within the boundary layer of leaves of plants that form the crop row (A cross section along the vertical plane perpendicular to the axis of the crop rows).

\subsection{Effects of Varying the Environmental Factors in the Greenhouse on the Microclimate in the Boundary Layer}

As seen above, the climate in the leaf boundary layer directly depends on the greenhouse climate control systems, i.e., heating, cooling, humidification and dehumidification, or air speed via the activation of greenhouse openings.

Using the model described above, we can evaluate the consequences on air temperature and humidity at $1 \mathrm{~mm}$ from the surface of the leaf in response to changes in the boundary conditions, i.e., temperature, humidity, and air velocity inside the greenhouse.

Simulations predict that when increasing the temperature of the ambient air of the greenhouse by $2{ }^{\circ} \mathrm{C}$, i.e., by changing the heat settings, the temperature at $1 \mathrm{~mm}$ under the leaf increases by $1.08^{\circ} \mathrm{C}$.

A decrease in air temperature inside the greenhouse by $2{ }^{\circ} \mathrm{C}$ when we activate the cooling system involves a reduction of $0.5{ }^{\circ} \mathrm{C}$ in the temperature at $1 \mathrm{~mm}$ under the leaf.

When increasing the air velocity inside the greenhouse by $0.2 \mathrm{~m} \mathrm{~s}^{-1}$ and $0.4 \mathrm{~m} \mathrm{~s}^{-1}$, respectively, either by blowing the surrounding air by means of fans or through air injection systems, i.e., using pipes pierced on the sides and placed in the row crops, we gain $0.5^{\circ} \mathrm{C}$ 
and $0.9{ }^{\circ} \mathrm{C}$ in temperature, respectively, and we lose $9 \%$ and $15 \%$ in humidity, respectively, at $1 \mathrm{~mm}$ under the leaf compared to the ambient air.

These results show that the climatic parameters of the ambient air inside the greenhouse and in the leaf boundary layer do not increase and decrease in the same direction in response to climate control system actions.

Understanding this relationship between the climate in these two environments, i.e., the climate in the leaf boundary layer and the greenhouse climate, allows to better manage the climate at the pest ecological niche level to carry out efficient pest control.

Knowing that small differences in temperature profiles among leaves can cause large variation in the metabolic rate and development time of insect eggs [26], the results of the present study on the climatic decoupling between the boundary layer of leaves and the ambient air in the greenhouse could be taken advantage of to propose climate control methods against pests and diseases.

This method will be based on the modification of the favorable climate of pest installation in the boundary layer of leaves by activating the cooling and heating systems or by playing with the degree of containment of the greenhouse, i.e., by closing or opening the greenhouse vents.

The developed model can be also used as a decision support tool by creating alarms based on the favorable climate to the development of pests and disease leading towards to new sustainable strategies of climate control limiting their installation. In fact, this spatiotemporal CFD-model describing the distributed climate within the greenhouse and especially in the boundary layer of plant leaves, could be used as a tool for sensitivity studies to draw up several assumptions to increase control of the microclimate in the level of plant cover to fight against pests.

It can be also used for a more effective risk prediction of the onset of epidemic outbreaks in the greenhouse and setting up alarms to activate air conditioning systems available in the greenhouse. This strategy will help fight insect pests in greenhouse plants by limiting the use of chemical products resulting in lower environmental impact.

The other application of the developed model is that by cross-referencing the distributed climate data from this model with the data from the spatial sampling of pests or beneficial insects, it is possible to better define the microclimatic conditions favorable to their installation.

\section{Conclusions}

Computational Fluid Dynamics (CFD) modeling tools allowed the exploration of the microclimate inside greenhouses and particularly at the level of the leaf boundary layer.

Using this model, the heterogeneity of the microclimate in the boundary layer of leaves, i.e., the ecological niche of pests and diseases, was considered and studied. This made it possible to show the discontinuity of the climatic conditions between the natural habitat of pests (BL) and the surrounding air, particularly during daytime.

This distributed climate modeling in the leaf boundary layer has provided crucial information on the climate conditions of the plant pest habitats. Superimposing maps of these climate conditions and those resulting from the spatial sampling of pest population can provide new information about their climate preferences and suggest new sustainable control strategies allowing for a more efficient pest control.

These control methods will base on the modification of the local climate to make it less favorable to the installation of pests.

Author Contributions: H.F. conceived the idea, developed the model collected and analyzed the data and drafted the paper. T.B. (Thierry Boulard), C.P., N.K., T.B. (Thomas Bartzanas), M.K., H.G. and I.-B.L. helped in analysis of the data, and finalization of the draft article. All authors commented on previous versions of the manuscript. All authors have read and agreed to the published version of the manuscript. 
Funding: This work received no specific grant from any funding agency in the public, commercial, or not-for-profit sectors.

Institutional Review Board Statement: Not applicable.

Informed Consent Statement: Not applicable.

Data Availability Statement: The authors declare that all other data supporting the findings of this study are available within the article.

Conflicts of Interest: The authors declare that they have no conflict of interest.

\section{References}

1. Boulard, T.; Mermier, M.; Fargues, J.; Smits, N.; Rougier, M.; Roy, J.C. Tomato leaf boundary layer climate: Implication for microbiological control of whiteflies in greenhouse. Agric. For. Meteorol. 2002, 110, 159-176. [CrossRef]

2. Jones, H.G. Plants and Microclimate: A Quantitative Approach to Environmental Plant Physiology, 3rd ed.; Cambridge University Press: Cambridge, UK, 2014; 407p.

3. Pincebourde, S.; Woods, H.A. Climate uncertainty on leaf surfaces: Perspectives on the leaf microclimate from biophysical ecology. Funct. Ecol. 2012, 26, 844-853. [CrossRef]

4. Woods, H.A.; Potter, K.A. Life in leaf boundary layers: How two millimeters of still air affects the performance and ecology of small insects. Integr. Comp. Biol. 2010, 50 (Suppl. 1), E193.

5. Sheriff, D.W. An infra-red psychrometer for detecting changes in the humidity of leaf boundary layers. J. Exp. Bot. 1973, 24, 641-647. [CrossRef]

6. Grace, J.; Wilson, J. Boundary-layer over a populus leaf. J. Exp. Bot. 1976, 27, 231-241. [CrossRef]

7. Boulard, T.; Fatnassi, H.; Roy, J.C.; Lagier, J.; Fargues, J.; Smits, N.; Rougier, M.; Jeannequin, B. Effect of Greenhouse Ventilation on Humidity of inside air and in leaf boundary-layer. Agric. For. Meteorol. 2004, 125, 225-239. [CrossRef]

8. Katsoulas, N.; Baille, A.; Kittas, C. Leaf boundary layer conductance in ventilated greenhouses. An experimental approach. Agric. For. Meteorol. 2007, 144, 180-192. [CrossRef]

9. Kimura, K.; Yasutake, D.; Yamanami, A.; Kitano, M. Spatial examination of leaf-boundary-layer conductance using artificial leaves for assessment of light airflow within a plant canopy under different controlled greenhouse conditions. Agric. For. Meteorol. 2020, 280, 107773. [CrossRef]

10. Nikolaou, G.; Neocleous, D.; Kitta, E.; Katsoulas, N. Estimation of aerodynamic and canopy resistances in a Mediterranean greenhouse based on instantaneous leaf temperature measurements. Agronomy 2020, 10, 1985. [CrossRef]

11. Ferro, D.N.; Southwick, E.E. Microclimates of small arthropods-estimating humidity within the leaf boundary-layer. Environ. Entomol. 1984, 13, 926-929. [CrossRef]

12. Roy, J.-C.; Vidal, C.; Fargues, J.; Boulard, T. CFD based determination of temperature and humidity at leaf surface. Electron. Agric. 2008, 61, 201-212. [CrossRef]

13. Fatnassi, H.; Poncet, C.; Bazzano, M.M.; Brun, R.; Bertin, N. A numerical simulation of the photovoltaic greenhouse microclimate. Sol. Energy 2015, 120, 575-584. [CrossRef]

14. Fatnassi, H.; Boulard, T.; Poncet, C.; Chave, M. Optimisation of greenhouse insect screening with Computational Fluid Dynamics. Biosyst. Eng. 2006, 93, 301-312. [CrossRef]

15. Boulard, T.; Wang, A. Experimental and numerical study on the heterogeneity of crop transpiration in a plastic tunnel. Comput. Electron. Agric. 2002, 34, 173-190. [CrossRef]

16. Fatnassi, H.; Boulard, T.; Bouirden, L. Simulation of climatic conditions in full-scale greenhouse fitted with insect-proof screens. Agric. For. Meteorol. 2003, 118, 97-111. [CrossRef]

17. Kacira, M.; Sase, S. Optimization of vent configuration by evaluating greenhouse and plant canopy ventilation rates under wind induced ventilation. Trans. ASAE 2004, 47, 2059-2067. [CrossRef]

18. Majdoubi, H.; Boulard, T.; Fatnassi, H.; Bouirden, L. Airflow and microclimate patterns in a one-hectare Canary type greenhouse: An experimental and CFD assisted study. Agric. For. Meteorol. 2009, 149, 1050-1062. [CrossRef]

19. Nebbali, R.; Roy, J.; Boulard, T.; Nebbali, R.; Roy, J.; Boulard, T. Dynamic simulation of the distributed radiative and convective climate within a cropped greenhouse. Renew. Energy 2012, 43, 111-129. [CrossRef]

20. Sase, S.; Kacira, M.; Boulard, T.; Okushima, L. Determination of porosity parameters for tomato canopy: An experimental study in a wind tunnel. Trans. ASABE 2012, 55, 1921-1927.

21. Tamimi, E.; Kacira, M.; Choi, C.; An, L. Analysis of climate uniformity in a naturally ventilated greenhouse equipped with high pressure fogging system. Trans. ASABE 2013, 56, 1241-1254.

22. Kichah, A.; Bournet, P.E.; Migeon, C.; Boulard, T. Measurements and CFD simulations of microclimate characteristics and transpiration of an Impatiens pot plant crop in a greenhouse. Biosyst. Eng. 2012, 112, 22-34. [CrossRef]

23. Boulard, T. Recent trends in protected cultivations-microclimate studies: A review. Acta Hortic. 2012, 957, 15-28. [CrossRef]

24. Schlichting, H. Boundary Layer Theory; McGraw-Hill: New York, NY, USA, 1979; 817p. 
25. Wang, S.; Boulard, T.; Haxaire, R. Air speed profiles in a naturally ventilated greenhouse. Agric. For. Meteorol. 1999, 96, 181-188. [CrossRef]

26. Potter, K.; Davidowitz, G.; Woods, H.A. Insect eggs protected from high temperatures by limited homeothermy of plant Leaves. J. Exp. Biol. 2009, 212, 3448-3454. [CrossRef] [PubMed] 